\title{
Kinesin Spindle Protein Inhibitor HR22C16 Sensitizes TRAIL-induced Apoptosis in Human Lung Cancer H1299 Cells
}

\author{
Mi-Kyung Hwang, Yong Ki Min, and Seong Hwan Kim* \\ Laboratory of Chemical Genomics, Pharmacology Research Center, Korea Research Institute of Chemical Technology, \\ P.O. Box 107, Yuseong-gu, Daejeon 305-600, Korea. E-mail: hwan@krict.re.kr \\ Received January 18, 2011, Accepted March 4, 2011
}

Key Words : Kinesin spindle protein, HR22C16, TRAIL resistance, Sensitizer, Lung cancer

Tumor necrosis factor (TNF)-related apoptosis-inducing ligand (TRAIL) triggers apoptosis by binding its receptors, TRAIL-R1 (also called death receptor 4, DR4) and TRAILR2 (DR5). ${ }^{1}$ The TRAIL-receptor complex then recruits the adaptor protein Fas-associated death domain (FADD) and procaspase- 8 to the cytoplasmic death domain of the receptors to form the death-inducing signaling complex, DISC. ${ }^{2}$ In DISC, procaspase- 8 undergoes autocatalytic activation, leading to activation of caspases such as caspase- $3 .^{3}$ However, DISC can be inhibited by its component, cellular FADD-like interleukin-1b-converting enzyme (FLICE) inhibitory protein (cFLIP) that is structurally similar to procaspase- $8 .{ }^{4}$

Interestingly, TRAIL is not toxic to most normal cells but triggers apoptosis in a variety of cancer cells. ${ }^{5}$ This property, i.e., selective cytotoxicity in cancer versus normal cells, makes TRAIL an excellent therapeutic candidate for cancer treatment, but several cancer cells are resistant to TRAIL. Therefore, resistance to TRAIL-induced apoptosis in cancer cells is a challenging issue for TRAIL-based anti-cancer therapeutic strategies.

In this study, we evaluated the effect of 180 enzyme inhibitors on cell viability in human lung cancer H1299 cells that are relatively resistant to TRAIL-induced apoptosis as well as in human lung fibroblast WI38 cells, and found that HR22C16 (Fig. 1a) sensitized TRAIL-induced apoptosis in H1299 cells, but not in WI38 cells; although TRAIL (100 $\mathrm{ng} / \mathrm{ml}$ ) alone was not cytotoxic to either H1299 or WI38 cells, the viability of H1299 cells, but not WI38 cells, was significantly inhibited when cells were treated with TRAIL plus HR22C16 (10 $\mu \mathrm{M})$ (Fig. 1b).

HR22C16 is a selective inhibitor of mitotic kinesin spindle protein (KSP or kinesin-5 motor protein, also called Eg5). ${ }^{6}$ The mitotic spindle motor protein KSP belongs to the kinesin superfamily and plays an essential role in centrosome separation and in the formation of a bipolar mitotic spindle. ${ }^{7}$ Inhibition of KSP function prevents centrosome separation and generates a monopolar spindle (monoaster) phenotype; this triggers mitotic arrest and leads to apoptosis. ${ }^{8} \mathrm{KSP}$ has thus been considered an attractive molecular target for cancer therapy, but its potential for sensitizing cancer cells to TRAIL-mediated apoptosis has not been studied yet. ${ }^{9}$ Therefore, we further evaluated the effect of other KSP inhibitors on the sensitization of H1299 cells to TRAIL-induced apop- tosis (Fig. 1b); trans-24 (structurally similar with HR22C16) and monastrol showed the TRAIL-sensitizing activity in H1299 cells, but both exhibited the cytotoxicity in WI38 cells. $S$-Trityl-L-cysteine exhibited the TRAIL-independent cytotoxicity in both H1299 and WI38 cells. These results suggested that among KSP inhibitors tested in this study, HR22C16 has the potential to sensitize H1299 cells to TRAIL-induced apoptosis.

The effect of TRAIL plus HR22C16 on the induction of apoptosis in H1299 cells was further analyzed (Fig. 2). Flow cytometric analysis revealed that $11.10 \%$ and $20.94 \%$ of cells were apoptotic when treated with 5 or $10 \mu \mathrm{M}$ HR22C 16 , respectively. However, in the presence of TRAIL (100 ng/ $\mathrm{mL}$ ), the percentage of apoptotic cells dramatically increased from $3.93 \%$ (TRAIL alone) to $32.31 \%$ and $45.08 \%$ when HR22C16 was also added at 5 and $10 \mu \mathrm{M}$, respectively.

To elucidate the mechanism underlying the sensitization effect of HR22C16 on TRAIL-induced apoptosis in H1299 cells, we examined the effect of HR22C16 on the activation of caspase- 8 that initially triggers TRAIL-induced extrinsic cell death. ${ }^{10}$ Caspase- 8 activity assay showed the synergistic effects of HR22C16 and TRAIL on the induction of apoptosis in H1299 cells (Fig. 3a). We next examined the involvement of inhibitors of apoptosis (IAP) proteins and Bcl-2 family proteins in the sensitization effect of HR22C16 on TRAIL-induced apoptosis (Fig. 3b). Western blot analysis revealed that expression levels of both the XIAP and survivin proteins were decreased by the combination of HR22C16 and TRAIL compared to HR22C16 alone. Among $\mathrm{Bcl}-2$ family proteins, Bcl-2 expression was also decreased by HR22C16 and TRAIL but not by each alone. Additionally, we examined the expression levels of proteins involved in the TRAIL-induced extrinsic cell death cascade (or in the formation of DISC), such as DR5, the cFLIPs and FADD (Fig. 3c). Interestingly, HR22C16 and TRAIL each induced expression of DR5, but its expression did not be increased further when they were added together. The expression levels of the cFILP $_{\mathrm{L}}$ and FADD proteins were not changed by HR22C16, TRAIL or their combination, but that of cFILP $_{s}$ decreased slightly with the addition of TRAIL and a higher concentration $(10 \mu \mathrm{M})$ of HR22C16.

Next, the effect HR22C16 plus TRAIL on NF- $\kappa$ B activation was evaluated using a luciferase reporter gene assay (Fig. 4). 
(a)<smiles>CCCCN1C(=O)C2Cc3c([nH]c4ccccc34)CC2C(=O)N1CCO</smiles>

HR22C16

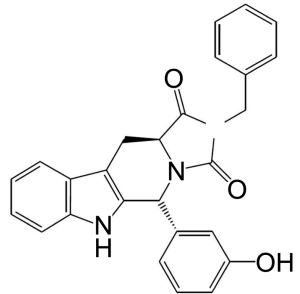

Trans-24

(b)

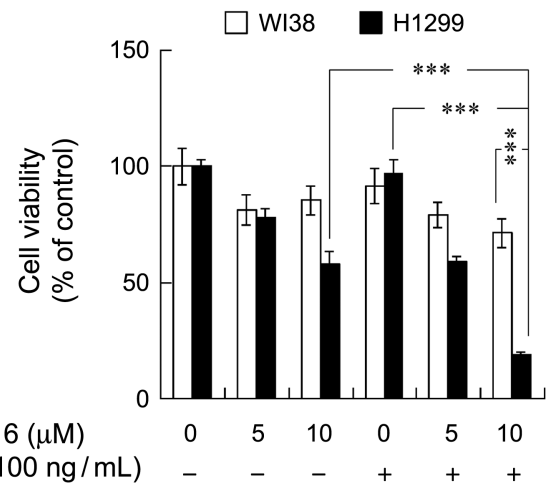

$\mathrm{HR} 22 \mathrm{C} 16(\mu \mathrm{M})$ TRAIL $(100 \mathrm{ng} / \mathrm{mL})$

Monastrol $(\mu \mathrm{M})$ TRAIL $(100 \mathrm{ng} / \mathrm{mL})$

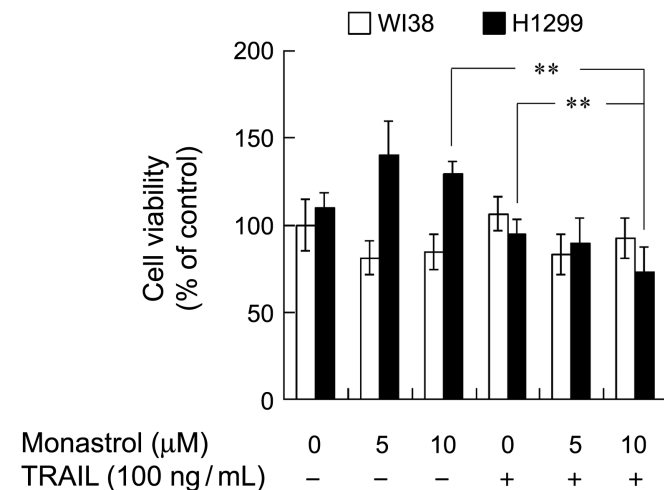

)

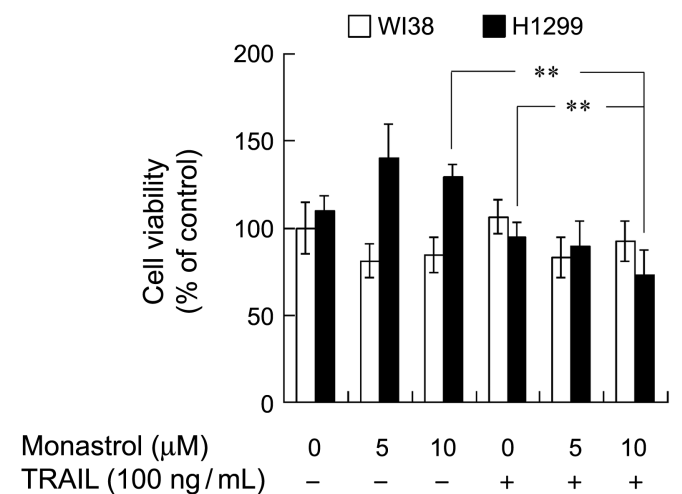<smiles>CCOC(=O)C1C(C)NC(=S)NC1c1cccc(O)c1</smiles>

Monastrol

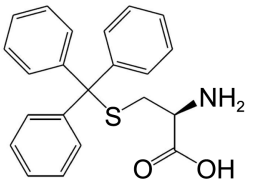

S-Trityl-L-cysteine

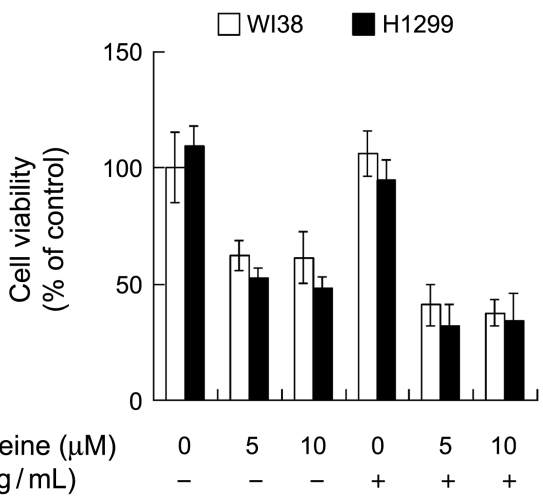

Figure 1. Chemical structures of KSP inhibitors (A) and their effect or in combination with TRAIL on the viability of H1299 and WI38 cells. Cells were incubated with each chemical alone or its combination with TRAIL $(100 \mathrm{ng} / \mathrm{mL})$ for 2 days and then the cell viability was evaluated by CCK-8 assay as described in 'Materials and Methods'. ${ }^{*}, P<0.05$; ${ }^{* *}, P<0.01$; *** $P<0.001$
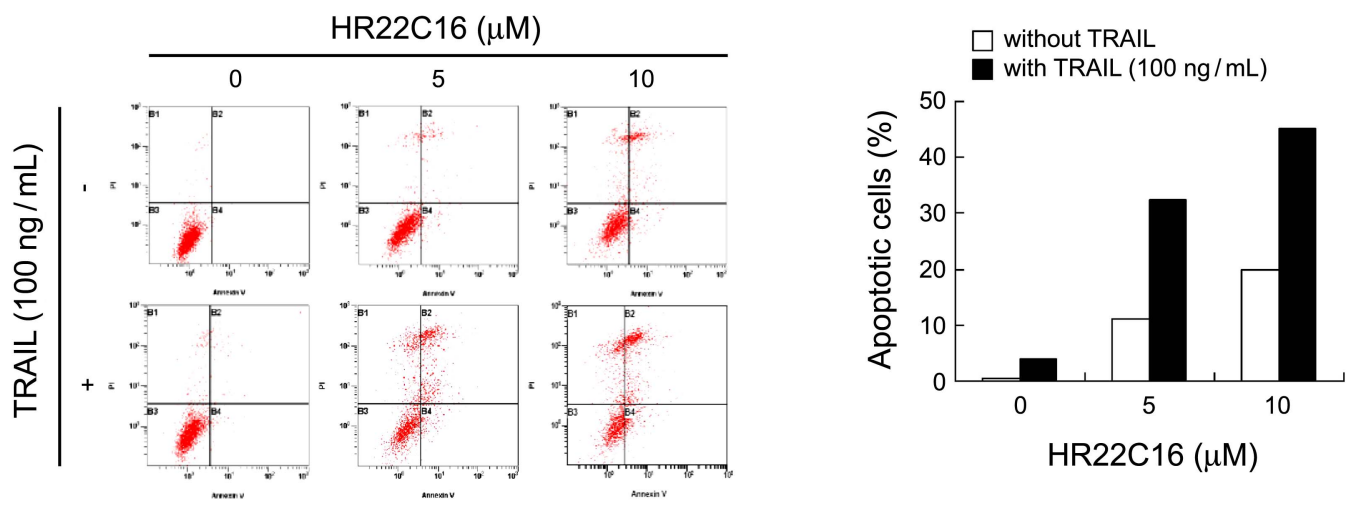

Figure 2. Sensitization effect of HR22C16 on TRAIL-induced apoptosis in H1299 cells. Cells $\left(2.4 \times 10^{5}\right.$ cells/well $)$ seeded in a 6-well plate were incubated with HR22C16 in the absence or presence of TRAIL $(100 \mathrm{ng} / \mathrm{mL})$ for $48 \mathrm{~h}$ and then the apoptotic cells were analyzed with flow cytometry as described in 'Materials and methods'.

Neither HR22C16 nor TRAIL alone changed NF-אB activity, but NF- $\kappa \mathrm{B}$ activity was significantly and dose-dependently inhibited by HR22C16 in the presence of TRAIL.

There are several strategies for overcoming resistance to 
(a)

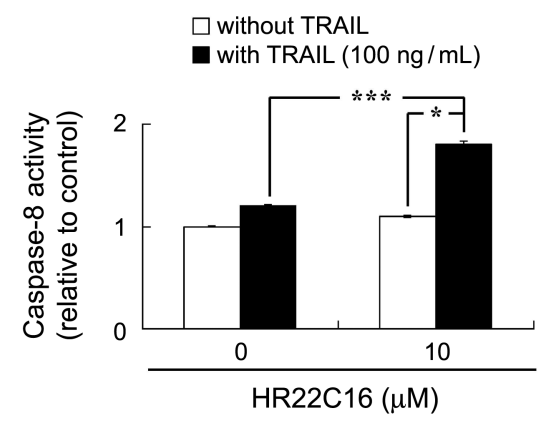

(b)

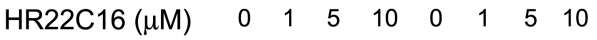
TRAIL $(100 \mathrm{ng} / \mathrm{mL})+{ }_{-}+{ }_{-}+++$

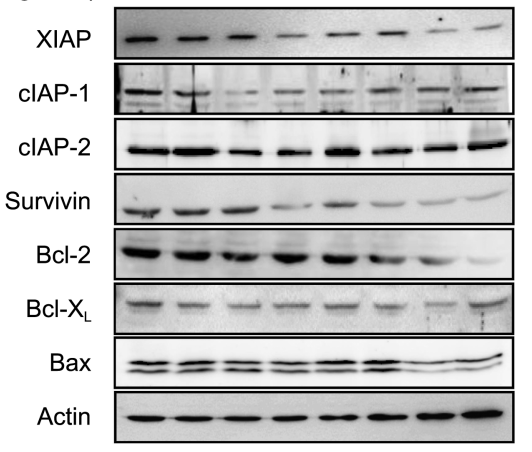

(c)

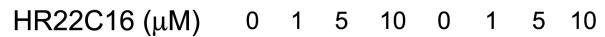
TRAIL $(100 \mathrm{ng} / \mathrm{mL})+{ }_{-}+\ldots++$

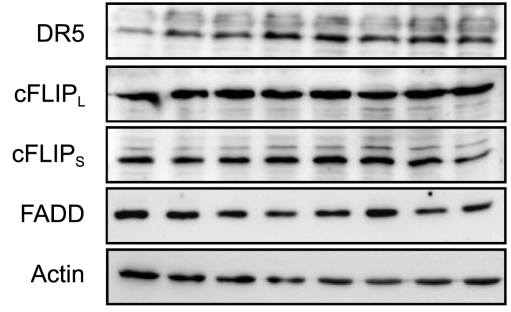

Figure 3. Effect of HR22C16 on apoptosis activation. (a) Effect of HR22C16 alone or in combination with TRAIL on capase-8 activity. Caspase- 8 activity assay was carried out as described in 'Materials and methods'. ${ }^{*}, P<0.05 ; * * *, P<0.001$. The effects of HR22C16 in the absence or presence of TRAIL on the protein expression levels of apoptosis-related (b) and DISC formationrelated molecules (c) were evaluated by western blot analysis as described in 'Materials and methods'.

TRAIL-induced apoptosis: up-regulation of molecules involved in TRAIL-induced extrinsic cell death signaling (such as DRs, FADD and caspases); down-regulation of molecules such as FLIP that inhibit DISC; or down-regulation of antiapoptotic molecules such as IAPs and Bcl family proteins. ${ }^{11}$ In the present study, the combination of HR22C16 and TRAIL enhanced caspase-8 activity and decreased expression of the XIAP, survivin and Blc-2 proteins more than HR22C16 alone. This suggested that XIAP, survivin and Bcl-2 expression may be involved in the HR22C16-mediated enhancement of TRAIL-induced apoptosis.

Down-regulation of anti-apoptotic molecules has been shown to enhance TRAIL-induced apoptosis. In particular, RNA interference-mediated knockdown of anti-apoptotic proteins such as Bcl-2, XIAP or survivin increased apoptosis

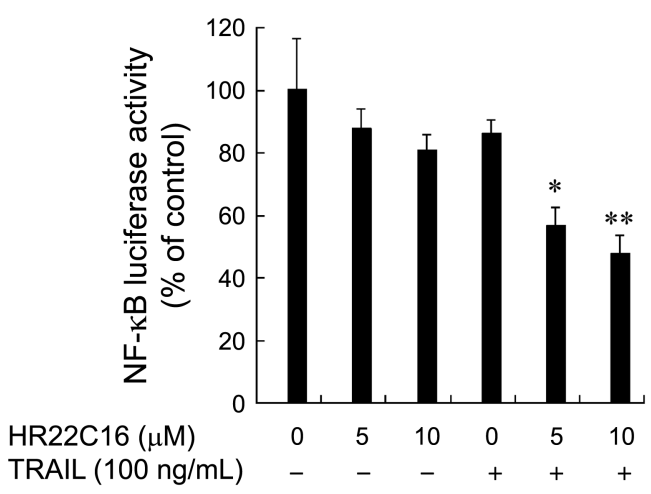

Figure 4. Effect of HR22C16 on NF- $\kappa B$ activation in the absence or presence of TRAIL. NF- $\mathrm{BB}$ luciferase activity assay was performed to evaluate the effect of HR22C16 on NF- $\mathrm{KB}$ activation in the absence or presence of TRAIL as described in 'Materials and methods'. *, $P<0.05 ; * *, P<0.01$.

in melanoma cells when added in combination with TRAIL. ${ }^{12}$ In contrast, increased expression of IAPs in cancer cells can confer resistance to TRAIL-induced apoptosis. ${ }^{13}$

XIAP is the most potent known inhibitor of caspase activity. In a study of the responses of different cell types to antimitotic drugs that target microtubules and KSP, sensitivity to apoptosis was correlated with loss of XIAP. ${ }^{14}$

As an IAP family member, survivin has also attracted attention because of its abundant expression in various types of cancers and its potential to regulate apoptosis: its overexpression confers cytoprotection against several apoptotic stimuli, whereas loss of survivin expression or function causes spontaneous apoptosis or sensitizes cancer cells to apoptotic stimuli. ${ }^{15}$ In addition, survivin is one of the chromosomal passenger protein complexes with multiple roles during cell division. ${ }^{16}$ Interestingly, survivin-deficient cells fail to complete cytokinesis, suggesting the contribution of survivin to accurate sister chromatid segregation and assembly/ stabilization of microtubules in late mitosis. ${ }^{17}$ Considering the role of survivin in the control of cytokinesis and its dosedependent down-regulation by HR22C16 in the presence of TRAIL, survivin might be one of the effectors that contribute to HR22C16-mediated sensitization to TRAIL-induced apoptosis in $\mathrm{H} 1299$ cells.

There is evidence that $\mathrm{Bcl}-2$ expression is involved in the sensitization effect of KSP inhibitors on TRAIL-induced apoptosis. Overexpression of $\mathrm{Bcl}-2$ confers protection against TRAIL in several cancer cell lines. ${ }^{18}$ In the present study, among Bcl-2 family members, the protein expression level of Bcl-2 was decreased more by the combination of HR22C16 with TRAIL than by each alone. This result suggested that Bcl-2 might mediate the lethal effects of HR22C16 in the presence of TRAIL.

Finally, we suggested the involvement of NF- $\mathrm{BB}$ in the sensitization effect of HR22C16 on TRAIL-induced apoptosis in H1299 cells. The effects of NF-KB on TRAIL signaling are still controversial; however, considering the report showing that pretreatment with a NF- $\mathrm{kB}$ inhibitor sensitized H1299 cells to TRAIL-induced apoptosis, the inhibition of 
NF- $\kappa B$ by the combination of HR22C16 and TRAIL could be related to the sensitization effect of HR22C16 on TRAILinduced apoptosis. ${ }^{19}$

In conclusion, KSP inhibitor HR22C16 sensitized H1299 cells to TRAIL-induced apoptosis by down-regulating the expression of apoptosis-related proteins (such as XIAP, survivin and $\mathrm{Bcl}-2$ ) and the activity of $\mathrm{NF}-\mathrm{kB}$, suggesting that the use of a combination of KSP inhibitors and TRAIL might be an efficient strategy for overcoming resistance to TRAIL in future clinical applications.

\section{Experimental Section}

Materials. Four KSP inhibitors including HR22C16 and soluble recombinant human TRAIL were purchased from Calbiochem (Germany) and Chemicon International Inc. (CA), respectively.

Cell Culture. Human lung cancer H1299 cells were cultured as described previously. ${ }^{20}$ Human lung WI38 cells (American Type Culture Collection, MD) were cultured in RPMI 1640 supplemented with $10 \%$ fetal bovine serum (FBS), $100 \mathrm{U} / \mathrm{mL}$ of penicillin and $100 \mu \mathrm{g} / \mathrm{mL}$ of streptomycin.

Cell Viability Assay. WI38 cells and H1299 cells were plated in a 384-well plate at 0.3 and $0.7 \times 10^{3}$ cells/well, respectively. After $24 \mathrm{~h}$, cells were incubated with HR22C 16 in the absence or presence of TRAIL ( $100 \mathrm{ng} / \mathrm{mL})$ for $48 \mathrm{~h}$. Then, cell viability was measured using Cell Counting Kit- 8 (Dojindo Molecular Technologies, ML). ${ }^{20}$

Apoptosis Analysis and Caspase-8 Activity Assay. Apoptosis and caspase- 8 activity were determined using ApoAlert annexin V apoptosis detection kit (Clontech, CA) and enzymatic fluorometric assay kit (R\&D systems, Inc., $\mathrm{MN}){ }^{20}$

Western Blot Analysis. Western blot analysis was performed as described previously. ${ }^{20}$

NF-KB Luciferase Activity Assay. Luciferase activity assay was performed as described previously. ${ }^{21}$ Briefly, H1299 cells $\left(1.4 \times 10^{3}\right.$ cells/well $)$ in a 96-well plate were transfected and incubated with HR22C16 in the absence or presence of TRAIL for $1 \mathrm{~h}$. The relative luciferase activity (firefly luciferase activity normalized with Renilla luciferase activity) was presented as $\%$ of control.

Statistical Analysis. Results were expressed as means \pm standard error of three independent experiments. Significance was determined using the Student's $t$-test and differences were considered significant when $P<0.05$.

Acknowledgments. This work was supported by a National
Research Foundation (NRF) grant (for 'Chemcial Genomics Research') funded by the National R\&D Program of the Korean Ministry of Education, Science, and Technology (MEST), No. 20100002073.

\section{References}

1. (a) Pan, G.; O'Rourke, K.; Chinnaiyan, A. M.; Gentz, R.; Ebner, R.; Ni, J.; Dixit, V. M. Science 1997, 276, 111. (b) Walczak, H.; Degli-Esposti, M. A.; Johnson, R. S.; Smolak, P. J.; Waugh, J. Y.; Boiani, N.; Timour, M. S.; Gerhart, M. J.; Schooley, K. A.; Smith, C. A.; Goodwin, R. G.; Rauch, C. T. EMBO J. 1997, 16, 5386.

2. Pennarun, B.; Meijer, A.; de Vries, E. G.; Kleibeuker, J. H.; Kruyt, F.; de Jong, S. Biochim. Biophys. Acta 2010, 1805, 123.

3. Cohen, G. M. Biochem. J. 1997, 326(Pt 1), 1.

4. Krueger, A.; Baumann, S.; Krammer, P. H.; Kirchhoff, S. Mol. Cell Biol. 2001, 21, 8247.

5. Walczak, H.; Miller, R. E.; Ariail, K.; Gliniak, B.; Griffith, T. S.; Kubin, M.; Chin, W.; Jones, J.; Woodward, A.; Le, T.; Smith, C.; Smolak, P.; Goodwin, R. G.; Rauch, C. T.; Schuh, J. C.; Lynch, D. H. Nat. Med. 1999, 5, 157.

6. Hotha, S.; Yarrow, J. C.; Yang, J. G.; Garrett, S.; Renduchintala, K. V.; Mayer, T. U.; Kapoor, T. M. Angew. Chem. Int. Ed. Engl. 2003, $42,2379$.

7. (a) Tao, W.; South, V. J.; Zhang, Y.; Davide, J. P.; Farrell, L.; Kohl, N. E.; Sepp-Lorenzino, L.; Lobell, R. B. Cancer Cell 2005, 8, 49. (b) Dagenbach, E. M.; Endow, S. A. J. Cell Sci. 2004, 117(Pt 1), 3. 8. (a) Vijapurkar, U.; Wang, W.; Herbst, R. Cancer Res. 2007, 67, 237. (b) Kapoor, T. M.; Mayer, T. U.; Coughlin, M. L.; Mitchison, T. J. J. Cell Biol. 2000, 150, 975.

9. Miglarese, M. R.; Carlson, R. O. Expert Opin. Investig. Drugs 2006, $15,1411$.

10. LeBlanc, H. N.; Ashkenazi, A. Cell Death Differ. 2003, 10, 66.

11. Zhang, L.; Fang, B. Cancer Gene Ther. 2005, 12, 228.

12. Chawla-Sarkar, M.; Bae, S. I.; Reu, F. J.; Jacobs, B. S.; Lindner, D. J.; Borden, E. C. Cell Death Differ. 2004, 11, 915.

13. (a) Ng, C. P.; Bonavida, B. Mol. Cancer Ther. 2002, 1, 1051. (b) Ng, C. P.; Zisman, A.; Bonavida, B. Prostate 2002, 53, 286.

14. Shi, J.; Orth, J. D.; Mitchison, T. Cancer Res. 2008, 68, 3269.

15. Altieri, D. C. Nat. Rev. Cancer 2003, 3, 46.

16. Adams, R. R.; Carmena, M.; Earnshaw, W. C. Trends Cell Biol. 2001, 11, 49 .

17. Yang, D.; Welm, A.; Bishop, J. M. Proc. Natl. Acad. Sci. USA 2004, 101, 15100

18. Fulda, S.; Meyer, E.; Debatin, K. M. Oncogene 2002, 21, 2283.

19. (a) Lee, K. Y.; Park, J. S.; Jee, Y. K.; Rosen, G. D. Exp. Mol. Med. 2002, 34, 462. (b) Moon, D. O.; Kim, M. O.; Choi, Y. H.; Kim, G. Y. Mol. Cancer Ther. 2010, 9, 1583. (c) Lirdprapamongkol, K.; Sakurai, H.; Suzuki, S.; Koizumi, K.; Prangsaengtong, O.; Viriyaroj, A.; Ruchirawat, S.; Svasti, J.; Saiki, I. In Vivo 2010, 24, 501. (d) Jane, E. P.; Premkumar, D. R.; Pollack I. F. Mol. Cancer Ther. 2011, 10, 198

20. Hwang, M. K.; Min, Y. K.; Kim, S. H. Biochem. Cell Biol. 2009, $87,919$.

21. Lee, S. U.; Choi, Y. H.; Kim, Y. S.; Min, Y. K.; Rhee, M.; Kim, S. H. Int. Immunopharmacol. 2010, 10, 298. 